Original article

\title{
Development and validation of tool to assess the perception, expectation \& satisfaction about the patient care services provided by the community pharmacist
}

\author{
Atiqulla Shariff, M Pharm, U.R. Rakshith, Pharm. D *, M.S. Srikanth, M Pharm, Ph.D \\ Department of Pharmacy Practice, JSS College of Pharmacy, JSSAHER, Mysuru, Karntaka 570015, India
}

A R T I C L E I N F O

\section{Keywords:}

Validation

Community pharmacist

Patient care services

Perceptions

Expectations and satisfactions

\begin{abstract}
A B S T R A C T
Problem considered: Apart from dispensing of medicines, the new generation community pharmacists are engaged in various extended community pharmacy services. The main endorsement of these services primarily depends on understanding the end-users' views about the quality of care provided. However, there are no validated tools available that can assess these parameters.

Methods: Therefore, we aimed to develop and validate a tool that can assess the perceptions, expectations and satisfactions of patient care services provided by the community pharmacist. Following a comprehensive literature search, a thirty-two-item scale was developed and was subjected for content validation.

Results: The item level content validity index (I-CVI) and scale level content validity index (S-CVI) was found to be $80 \%$. The Cronbach's alpha score was 0.8 , suggesting a satisfactory co-efficient of reliability.

Conclusion: The scale to assess the perceptions, expectations and satisfactions of patient care services provided by the community pharmacist was developed and validated.
\end{abstract}

\section{Introduction}

Community pharmacist are the most accessible healthcare professionals and they play a vital role in patients' medicine related needs. Dispensing of medicines is the primary role of the community pharmacist. ${ }^{1}$ In addition, provision of pharmaceutical care services of new generation community pharmacists includes medication therapy management, medication synchronization, patient education, immunization services, drug information services, health promotion, and health screening services. ${ }^{2,3}$ These extended community pharmacy services are well recognized in many developed countries. In India, many community pharmacists provide all these services routinely. The main endorsement of these services primarily depends on understanding the end-users' views about the quality of care provided. ${ }^{4}$ In many countries, there are well structured systems do exist for evaluation of patient care services provided by the community pharmacist. ${ }^{5}$ However, literature search revealed lack of published data in this regard from India. Therefore, we realized a need for development of a tool that can assess the perceptions, expectations and satisfaction of local population on patient care services provided by Indian community pharmacists.

\section{Methods}

\subsection{Tool development}

We performed a comprehensive literature search in online search engines to identify the published literatures that assessed the perceptions, and/or expectations and/or satisfactions of patient care services or pharmaceutical care services of community pharmacists. We reviewed the questionnaires and/or scales and/or tools that were used in the published literature and pooled a total of twenty-five items for the draft tool. After removing duplications and irrelevant items and developing new items we consolidated a total of thirty-two items. Further, these items were categorized into perception, expectation and satisfaction domains.

The final tool consisted of nine, fourteen and nine items in perception, expectation and satisfaction domains respectively. In perception domain there were nine items that basically seeking the responses related to the perception of consumers about the role of community pharmacists in patient care services. The expectation domain consists of fourteen items related to expectations regarding delivery of healthcare

\footnotetext{
* Corresponding author. Department of Pharmacy Practice, JSS College of Pharmacy, Mysuru, JSSAHER, Karnataka, 570015, India.

E-mail addresses: atiqcpp@gmail.com (A. Shariff), Urrakshith@jssuni.edu.in, mssrikanth@jssuni.edu.in (U.R. Rakshith), mssrikanth@jssuni.edu.in (M.S. Srikanth)
} 
service by the community pharmacist. Whereas, the satisfaction domain consists of nine items seeking the consumers responses related to satisfaction about the patient care services provided by the pharmacist. The possible responses for each of the items were set following 5-point Likert-scale model namely, strongly agree, agree, no opinion/not sure/ neither agree nor disagree, disagree and strongly disagree. The response levels were numerically coded as $5,4,3,2$, and 1 so that the higher numerical code indicating positive whereas the lower numerical code indicating negative responses about each item in the tool.

\subsection{Tool validation}

Thus, prepared tool was subjected for content validation. The validation team consisted of fifty experts that included community pharmacist, community medicine doctors, academicians and research scholars from pharmacy practice department and representatives from general public. Team members were provided with the tool, explained about the purpose and the process of validation. Team members were requested to validate each item of the tool with respect to relevance, clarity, simplicity and ambiguity following four-point scale as suggested by Yaghmaie F. ${ }^{6}$

\subsection{Statistical analysis}

We used Cronbach's alpha (coefficient of reliability) to assess the content validity index (CVI). A Cronbach's alpha value of $\geq 0.8$ in each domain namely, relevance, clarity, simplicity and ambiguity as well as for overall scale was considered adequate or satisfactory. ${ }^{6,7}$ We used Statistical Package for Social Sciences (version 24.0) for all the statistical calculations.

\section{Results}

A total of fifty experts, twenty-eight from health science background and twenty-two from non-health science background validated the tool. The demographic details of validation team members are presented in Table 1.

The item-content validity index (I-CVI) for each items in all the three domains were estimated. Initially, the I-CVI scores for the items in the perception domain were found to be unsatisfactory, with respect to clarity (47.5\%), simplicity (65.7\%) and ambiguity (52\%). Therefore, we rephrased the items in this domain to make the items clearer, simple and avoid ambiguity and I-CVI was assessed again. In the second phase of validation, the I-CVI scores were found to be satisfactory $(\geq 80 \%)$ for all the items of the tool. Further, we assessed the Cronbach's alpha of the final version of the scale and the overall score was more than 0.8 . The details of I-CVI scores in both the phases and Cronbach's alpha score of the final version of the scale are presented in Table 2.

\section{Discussion}

The main endorsement for the services provided in the community pharmacies primarily depend on the patient's views, perception, and

Table 1

Demographic details of validation team members.

\begin{tabular}{lll}
\hline Demographic details & & Frequency (\%) \\
\hline Mean age of participants & $40.3 \pm 11.5$ years & - \\
Gender & Male & $27(54)$ \\
& Female & $23(46)$ \\
Qualification & Doctorate & $5(10)$ \\
& Master's degree & $18(36)$ \\
& Bachelor's degree & $19(38)$ \\
Specialization & Diploma & $8(16)$ \\
& Health science & $28(56)$ \\
& Non-health science & $22(44)$ \\
\hline
\end{tabular}

Table 2

I-CVI and Cronbach' alpha scores in three domains of scale.

\begin{tabular}{|c|c|c|c|c|c|c|}
\hline \multirow{3}{*}{$\begin{array}{l}\text { Criteria for } \\
\text { validation }\end{array}$} & \multicolumn{6}{|c|}{ Domains of scale } \\
\hline & \multicolumn{2}{|c|}{ Perceptions } & \multicolumn{2}{|c|}{ Expectations } & \multicolumn{2}{|c|}{ Satisfaction } \\
\hline & Phase-1 & Phase-2 & Phase-1 & Phase-2 & Phase-1 & $\begin{array}{l}\text { Phase- } \\
2\end{array}$ \\
\hline \multicolumn{7}{|c|}{ I-CVI (\%) scores } \\
\hline Relevance & $\begin{array}{l}3.93 \\
(97.5)\end{array}$ & $\begin{array}{l}3.95 \\
(97.5)\end{array}$ & $\begin{array}{l}3.46 \\
(86.5)\end{array}$ & $\begin{array}{l}3.49 \\
(87.2)\end{array}$ & $\begin{array}{l}3.84 \\
(95)\end{array}$ & $\begin{array}{l}3.55 \\
(88)\end{array}$ \\
\hline Clarity & $\begin{array}{l}1.91 \\
(47.5)\end{array}$ & $\begin{array}{l}3.28 \\
(82)\end{array}$ & $\begin{array}{l}3.79 \\
(94.7)\end{array}$ & $\begin{array}{l}3.89 \\
(97.2)\end{array}$ & $\begin{array}{l}3.27 \\
(80)\end{array}$ & $\begin{array}{l}3.67 \\
(90)\end{array}$ \\
\hline Simplicity & $\begin{array}{l}2.63 \\
(65.7)\end{array}$ & $\begin{array}{l}3.21 \\
(80.2)\end{array}$ & $\begin{array}{l}3.95 \\
(98.7)\end{array}$ & $\begin{array}{l}3.98 \\
(99.5)\end{array}$ & $3.4(85)$ & $\begin{array}{l}3.52 \\
(88)\end{array}$ \\
\hline Ambiguity & $\begin{array}{l}2.08 \\
(52)\end{array}$ & $\begin{array}{l}3.26 \\
(81.5)\end{array}$ & $\begin{array}{l}3.96 \\
(99)\end{array}$ & $\begin{array}{l}3.98 \\
(99.5)\end{array}$ & $\begin{array}{l}3.46 \\
(86.5)\end{array}$ & $\begin{array}{l}3.67 \\
(90)\end{array}$ \\
\hline $\begin{array}{l}\text { Avg. I-CVI } \\
(\%)\end{array}$ & $\begin{array}{l}2.64 \\
(66)\end{array}$ & $\begin{array}{l}3.42 \\
(85.5)\end{array}$ & $\begin{array}{l}3.92 \\
(98)\end{array}$ & $\begin{array}{l}3.96 \\
(99)\end{array}$ & $\begin{array}{l}3.49 \\
(86.6)\end{array}$ & $\begin{array}{l}3.71 \\
(92)\end{array}$ \\
\hline \multicolumn{7}{|c|}{$\overline{\text { Cronbach's alpha scores of the final version of tool }}$} \\
\hline Relevance & 0.89 & & 0.98 & & 0.96 & \\
\hline Clarity & 0.85 & & 0.86 & & 0.86 & \\
\hline Simplicity & 0.84 & & 0.84 & & 0.84 & \\
\hline Ambiguity & 0.97 & & 0.81 & & 0.87 & \\
\hline Overall & 0.88 & & 0.87 & & 0.87 & \\
\hline
\end{tabular}

satisfaction. There are various studies conducted previously to assess these parameters, and different studies assessed different parameters. Few studies assessed perceptions and expectations while other assessed only satisfactions. Some studies assessed the parameters on yes or no type of scale while majority used Likert scale. . $^{3,4,8-10}$

However, literature search revealed an absence of a validated tool to assess these parameters. A comprehensive literature search helped us to identify and categorize various items that has been used in the published literature into, perceptions, expectation and satisfaction domains. Finally, a thirty-two-item scale was developed that was subjected for validation.

Content validity is the degree to which the elements of an assessment instrument are relevant to and representative of the targeted construct for a particular assessment purpose. ${ }^{7}$ We used a four-point scale as suggested by the Yaghmaie F criteria to measure the content validity. ${ }^{6}$ This scale reflects the four major components of any assessment instrument namely, relevancy of the tool to assess or measure what is intended to be measured, clarity of the items to the assesse, simpler items that can be understood by the assesse and that can avoid ambiguities while assessing the components.

In the first phase of the validation process, the items in expectations and satisfaction had a I-CVI score of $\geq 80 \%$ with respect to relevance, clarity, simplicity and ambiguity. Though, the items in the perception domain had a satisfactory score with respect to relevance (97.5\%), the ICVI scores for clarity, simplicity and ambiguity were very low. The average score for items clarity in these domains was around 2, suggesting that, item need some revision. Similarly, the average scores for items simplicity and ambiguity were 2.63 and 2.08 respectively. This suggests that the items are simple but needs some/minor revision.

A second phase of validation was conducted after rephrasing the items of perception domain to make them clearer, simpler and to avoid ambiguities. The validation team members were provided with the modified/updated tool and requested to validate the same. The I-CVI scores were improved after the items were modified or rephrased. A satisfactory score of $\geq 80 \%$ was obtained for all the items in all the three domains with respect to relevancy, clarity, simplicity and in avoiding ambiguity. Further, we estimated Cronbach's alpha to understand the consistency among the experts in validating the tool. We observed Cronbach's alpha of 0.8 for all the domains in all the four criteria. A thirty-two-item scale to assess the perceptions, expectations and satisfactions about patient care services provided by the community 
pharmacists was developed and validated. This scale will be a useful research tool in assessing the pharmacy services provided by the community pharmacists.

\section{Source of funding}

None.

\section{Declaration of competing interest}

None.

\section{Acknowledgement}

Authors thank all the members of validation team and all the administrators of JSS College of Pharmacy, and JSS Academy of Higher Education \& Research for their help and encouragement provided for this research.

\section{References}

1 American Society of Health-System Pharmacists. ASHP guidelines: minimum standard for pharmacies in hospitals. Am J Health Syst Pharm. 2013;70:1619-1630.

2 International Pharmaceutical Federation (FIP). Good Pharmacy Practice (GPP) in Developing Countries; Recommendations for Step-wise Implementation; 1997. Available from: https://www.fip.org/files/fip/Statements/GPP\%20recommendations.pdf. Accessed June 2, 2021

3 Abdelmoneim I Awad, Al-Rasheedi Altaf, Lemay Jacinthe. Public perceptions, expectations, and views of community pharmacy practice in Kuwait. Med Princ Pract. 2017;26:438-446.

4 Jose Jimmy, Shukili Marwa Nasser Al, Jimmy Beena. Public's perception and satisfaction on the roles and services provided by pharmacists in Sultanate of Oman: a cross-sectional study. Saudi Pharmaceut J. 2015;23:635-641.

5 American Society of Health-System Pharmacists. ASHP statement on the role of the medication safety leader. Am J Health Syst Pharm. 2013;70:448-452.

6 Yaghmaie F. Content validity and its estimation. J Med Educ. 2003;3(1):25-27.

7 Rusticus S. Content validity. In: Michalos AC, ed. Encyclopedia of Quality of Life and Well-Being Research. Dordrecht: Springer; 2014.

8 Larasanty LPF, Cahyadi MF, Sudarni NMR, Wirasuta IMAG. Patient satisfaction with pharmaceutical care services provided at primary-level and secondary-level health facilities in Indonesia's health coverage system. 2019;33:1.

9 Hajj MSE, Salem S, Mansoor H. Public's attitude towards community pharmacy in Qatar pilot study. Patient Prefer Adherence. 2011;5:405-422.

10 Workye M, Admasu S, Abura Y, et al. Client's expectation from and satisfaction with medicinal retail outlets in Gondar town, north-western Ethiopia: a cross-sectional study. Intergr Pharm Res Pract. 2015;4:1-12. 